\title{
Demarcation of Structural Domains in Fractured Rock Masses Using a Three-Parameter Simultaneous Analysis Method
}

\author{
Xin Zhou $\mathbb{D}^{1},{ }^{1}$ Jianping Chen $\mathbb{D}^{1},{ }^{1}$ Yunkai Ruan, ${ }^{2}$ Wen Zhang, ${ }^{1}$ Shengyuan Song, ${ }^{1,3}$ \\ and Jiewei Zhan ${ }^{1}$ \\ ${ }^{1}$ College of Construction Engineering, Jilin University, Changchun 130026, China \\ ${ }^{2}$ College of Transportation and Civil Engineering, Fujian Agriculture and Forestry University, Fuzhou 350002, China \\ ${ }^{3}$ State Key Laboratory of Geohazard Prevention and Geoenvironment Protection, Chengdu University of Technology, \\ Chengdu 610059, China
}

Correspondence should be addressed to Jianping Chen; chenjpwq@126.com

Received 6 August 2018; Revised 28 October 2018; Accepted 18 November 2018; Published 6 December 2018

Academic Editor: Flavio Stochino

Copyright (c) 2018 Xin Zhou et al. This is an open access article distributed under the Creative Commons Attribution License, which permits unrestricted use, distribution, and reproduction in any medium, provided the original work is properly cited.

\begin{abstract}
A structural domain represents a volume of a rock mass with similar mechanical and hydrological properties. To demarcate structural domains (or statistically homogeneous regions) in fractured rock masses, this study proposes a three-parameter simultaneous analysis method (3PSAM) that simultaneously considers rock fracture orientation, trace length, and aperture to evaluate statistical homogeneity between two regions. First, a 102-patch three-dimensional Schmidt net, which represents a new comprehensive classification system, is established to characterize rock fractures based on their orientation and aperture. Two populations of rock fractures can then be projected to the corresponding patches. Second, the Wald-Wolfowitz runs test is used to measure the similarity between the two populations by considering the fracture trace lengths. The results obtained by applying the 3PSAM to seven simulated fracture populations show that the homogeneity is influenced by both the distributions of the fracture parameters and the sequences of the fracture parameters. The influence of a specific combination sequence makes it impractical to analyze the rock fracture parameters individually. Combined with previous methods, the 3PSAM provides reasonable and accurate results when it is applied to a fractured rock slope engineering case study in Dalian, China. The results show that each fracture population should be identified as an independent structural domain when using the 3PSAM. Only the 3PSAM identifies the west exploratory trench 2 and the east exploratory trench as being nonhomogeneous because the difference in the aperture of the two fracture populations is considered. The benefit of the 3PSAM is that it simultaneously considers three parameters in the demarcation of structural domains.
\end{abstract}

\section{Introduction}

A structural domain represents a volume of a rock mass with similar mechanical and hydrological properties. The demarcation of structural domains in fractured rock masses is a basic step in fractured rock modeling and rock engineering design. Fractures cause rock masses to be discontinuous, nonhomogeneous, and anisotropic, which make the properties of rock masses have randomness and uncertainty. Fortunately, because of their formation process, rock fractures always have some regularities. These regularities are important to rock engineering because they have a significant influence on the mechanical and hydraulic behaviors of rock masses. Therefore, the demarcation of structural domains usually includes two steps:

The first step is to select rock fracture parameters to build a comprehensive classification system. An adequate description of rock fractures is critical to structural domain demarcation. According to ISRM (1978) [1], a complete description of rock fractures should include the location, type, orientation (dip angle and dip direction), spacing, persistence, roughness, aperture, infilling, and seepage. However, simultaneously considering all of these parameters in the demarcation of structural domains remains a difficult problem.

The second step is to demarcate structural domains based on the selected fracture parameters. The demarcation 
process can be accomplished using discrepancy and similarity measures, which are widely used in applied statistics. For example, Guo et al. [2] proposed a restricted similarity measure for content-based image retrieval using Euclidean distance together with support vector machine and AdaBoost techniques. Vert et al. [3] introduced a kernel method, which is often used in the similarity measures. Martino et al. [4] derived the possible effective sample size (ESS) functions for important sampling (IS) based on different discrepancy measures. Therefore, the demarcation of structural domains can be considered an evaluation of the similarity of the fractures between two regions.

Structural domains are often demarcated based on fracture orientation. Several classical methods are widely used. Miller [5] proposed a chi-square test to determine structural domains. A Schmidt net is divided into 34 patches, and a contingency table analysis is then used to compare the number of poles located in the corresponding patches. Mahtab and Yegulalp [6] subsequently developed a similarity test to evaluate homogeneity. The orientations of fractures are plotted on an upper hemisphere surface, which is divided into 100 equal-area quadrilateral patches. The similarity of two populations is then determined using a Poisson randomness threshold. Kulatilake et al. [7] presented an approach to incorporate results of equal-area plots and Miller's method with new interpretations to establish a demarcation line between homogeneity and nonhomogeneity. Kulatilake et al. [8] applied an improved version of Miller's method [5] to investigate the statistical homogeneity of rock masses that was successfully used in a tunnel near the Three Gorges Dam Site. Martin and Tannant [9] devised a method of using a parameter known as the correlation coefficient to evaluate the degree of the similarity between two populations. Recently, Li et al. $[10,11]$ adopted the Kolmogorov-Smirnov and Wilcoxon rank sum nonparametric tests to evaluate the homogeneity of the structural populations collected from adits at the Songta Dam Site. These studies have significantly assisted in the demarcation of structural domains by considering fracture orientations. However, these studies suffer from the inability to consider more than one parameter at a time. As a result, fractures within the same domain may have different mechanical or hydrological properties.

In some cases, other fracture parameters should be simultaneously considered because fracture orientation is not the only influencing factor. Several studies have used multiple fracture parameters to demarcate structural domains. Kulatilake et al. [12] used the box fractal dimension as a measure of the statistical homogeneity of fractured rock masses. The box fractal dimension can consider the combined effect of the fracture-size distribution and fracture density. Zhou and Maerz [13] used multidimensional clustering to demarcate fracture sets and structural domains by simultaneously considering orientation, spacing, and roughness. Quoc et al. [14] divided the fracture patterns of rock masses into homogeneous regions using correlation coefficients and rock quality designation values. Song et al. $[15,16]$ introduced the Wald-Wolfowitz runs test for determining structural domain boundaries within a rock mass by considering fracture orientation and trace length. Li et al. [17] used the correlation coefficient to quantify the degree of similarity between two populations by considering nine fracture parameters; however, they are not considered simultaneously. Based on magnification and reduction methods, Zhang et al. [18] found that size effects play an important role in the identification of structural domains. Song et al. [19] adopted the correlation coefficient and the Wald-Wolfowitz runs test to evaluate the homogeneity of structural domains by considering fracture orientation, trace length, and trace type. These studies used multivariate methods to demarcate structural domains by considering multiple fracture parameters. Rigorous and reasonable results were derived from these studies. However, some multivariate methods neglect the influence of sequences of multiple fracture parameters; that is, fracture parameters should be treated simultaneously to identify the similarity between different regions, as suggested by Zhou and Maerz [13]. The simultaneous analysis of more than two parameters in the demarcation of structural domains has rarely been discussed in the literature.

Therefore, this paper presents a three-parameter simultaneous analysis method (3PSAM) to evaluate the homogeneity of fractures from simulated data and field data. The method divides fractures into patches based on the fracture orientation (dip angle and dip direction), trace length, and aperture. Using the Wald-Wolfowitz runs test, the dip angle, dip direction, trace length, and aperture of fractures can be treated simultaneously, which allows the interactions between fracture parameters to be taken into account. The simultaneous analysis of the three parameters is the new consideration in the 3PSAM. The procedures of this approach are as follows:

(1) A 102-patch three-dimensional (3D) Schmidt net (Section 2.1), which represents a new comprehensive classification system, is established to characterize rock fractures based on their orientation and aperture

(2) The fractures projected in each patch are ranked by their trace length, and the structural domains can then be demarcated according to the WaldWolfowitz runs test (Section 2.2)

\section{Methodology}

2.1. 3D Schmidt Net. Fracture orientation is a parameter that includes two variables: dip and dip direction. The orientation can be plotted on a Schmidt net as a pole. The pole coordinate system of the Schmidt net is a $2 \mathrm{D}$ plane that can only represent two variables. Therefore, a 3D Schmidt net is proposed to represent three variables in a coordinate system. The importance of using the 3D Schmidt net is that it can simultaneously consider three variables. This feature helps to build a new comprehensive classification system based on fracture orientation and aperture. As shown in Figure 1, the 3D Schmidt net has cylindrical polar coordinates. The three coordinates $(r, \theta, z)$ of a point $\mathrm{P}$ are defined as follows: 


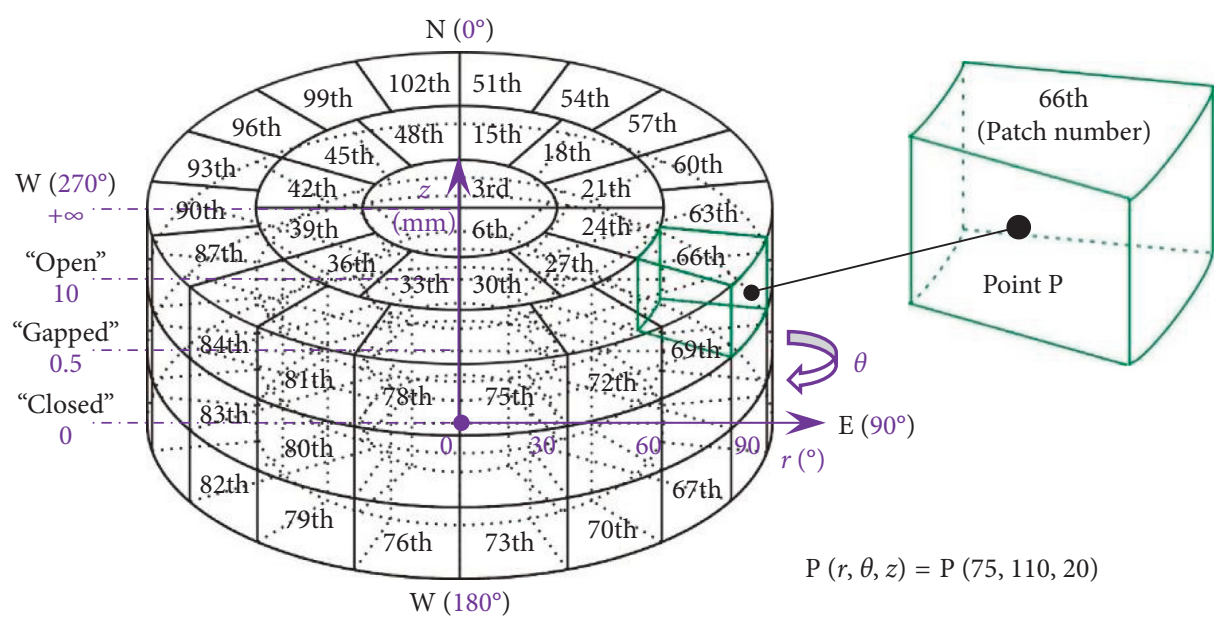

FIgure 1: Example of a 3D Schmidt net with cylindrical polar coordinates.

(1) The radial distance $r\left(0^{\circ}, 90^{\circ}\right)$ is the dip angle of the fracture, which is measured from the $z$-axis $\left(0^{\circ}\right)$ to the point $\mathrm{P}\left(\mathrm{r}^{\circ}\right)$

(2) The azimuth $\theta\left(0^{\circ}, 360^{\circ}\right)$ is the dip direction of the fracture, which is measured between north $\left(0^{\circ}\right)$ on a horizontal plane and the line from the origin to the projection of $P\left(\theta^{\circ}\right.$, clockwise $)$ on the horizontal plane

(3) The height $z$ is the aperture of the fracture, which is measured from the bottom plane $(0 \mathrm{~mm})$ to the fracture $P(z \mathrm{~mm})$

The horizontal section of cylindrical polar coordinates is divided based on Miller's 34-patch network (Figure 2) [5]. In the $z$-axis direction, the fracture apertures are described by the terms listed in Table 1. To illustrate this method, the hydraulic conductivity is neglected in this study. Therefore, there is no need to divide the fracture apertures into numerous intervals. Hence, the $z$-direction is divided into three intervals ("Closed," "Gapped," and "Open" features) $[1,20]$ from the bottom layer to the top layer (Figure 1) according to Table 1. The 3D Schmidt net is divided into 102 patches as shown in Figure 1, and the numbering of the patches is as follows:

(1) From bottom to top

(2) Clockwise, starting from north $\left(0^{\circ}\right)$

(3) From inside to outside

(4) From 1 to 102

Using cylindrical polar coordinates, any fracture with a dip, dip direction, and aperture can be uniquely plotted as a point in one of the 102 patches of the 3D Schmidt net. It should be noted that the aperture can be described by any classification method for different projects. For other classification methods of the aperture, the key is to determine the cutoff values between the intervals in the $z$-direction, as shown in Figure 1. The 3D Schmidt net can then be established accordingly.

2.2. Wald-Wolfowitz Runs Test. The Wald-Wolfowitz runs test is a method that utilizes a runs approach to examine the

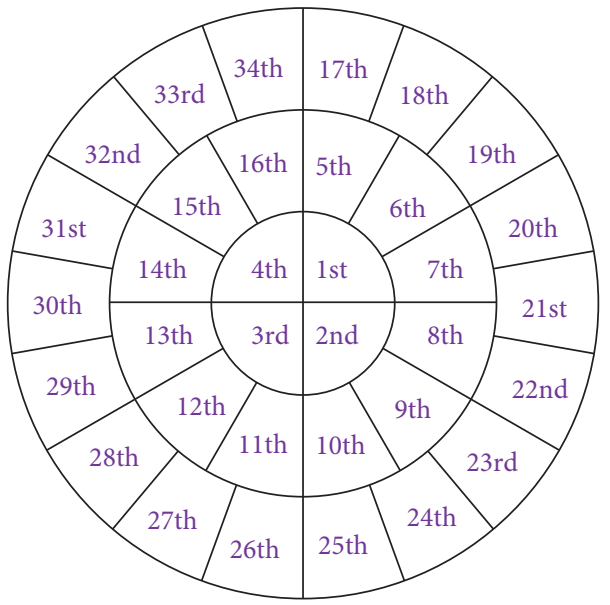

Figure 2: Thirty-four equal-area patches.

Table 1: Aperture dimensions [1, 20].

\begin{tabular}{lcc}
\hline Aperture & Description & Feature \\
\hline$<0.1 \mathrm{~mm}$ & Very tight & \\
$0.1-0.25 \mathrm{~mm}$ & Tight & "Closed" \\
$0.25-0.5 \mathrm{~mm}$ & Partly open & \\
$0.5-2.5 \mathrm{~mm}$ & Open & "Gapped" \\
$2.5-10 \mathrm{~mm}$ & Moderately wide & \\
$1-10 \mathrm{~cm}$ & Very wide & "Open" \\
$10-100 \mathrm{~cm}$ & Extremely wide & \\
$>1 \mathrm{~m}$ & Cavernous & \\
\hline
\end{tabular}

similarity between two populations [21]. The test is used to examine the null hypothesis $\left(H_{0}\right)$ that two populations $(X$ and $Y$ ) have the same distribution versus the alternative hypothesis $\left(H_{1}\right)$ that the distributions of the two populations differ in some way. To test $\mathrm{H}_{0}, x_{i}(i=1,2,3, \ldots, m)$ and $y_{j}(j=$ $1,2,3, \ldots, n)$ are assumed to be independent random fractures from populations $X$ and $\mathrm{Y}$, respectively; $m$ and $n$ are number of fractures in populations $X$ and $Y$, respectively; $m_{s}$ and $n_{s},(1 \leq s \leq 102)$ are number of fractures in the $s$ th patch of populations $X$ and $Y$, respectively. Each fracture is 
characterized by four variables (dip, dip direction, trace length, and aperture). A matrix, which consists of $m$ (or $n$ ) rows and four columns, is used to describe the population $X$ (or $Y$ ). Each row vector represents a fracture that contains the four variables, and each column vector represents one of the variables that contains $m$ (or $n$ ) rows. The detailed procedures of the Wald-Wolfowitz runs test are as follows [22-24]:

(1) The row vectors (fractures) from populations $X$ and $\mathrm{Y}$ are combined into a population $Z$. Assume that $z_{k}$ $(k=1,2,3, \ldots, m+n)$ are the fractures from population $Z$. First, the patches are arranged in ascending order based on their patch numbers (i.e., from the 1 st patch to the 102 nd patch). Second, the fractures of the $s$ th $(1 \leq s \leq 102)$ patch of the two populations are merged and ranked in ascending order of trace length, as shown in Table 2. The sequence of $z_{k}\left(z_{1}, z_{2}, z_{3}, \ldots, z_{m+n}\right)$ can be determined by trace length and patch number.

(2) Use $T_{k}$ to track the source of each fracture $\left(z_{k}\right)$ in the population $Z$. If $z_{k}$ is from $X, T_{k}=1$; if $z_{k}$ is from $Y, T_{k}$ $=0,(k=1,2,3, \ldots, m+n)$. The sequence of $T_{k}\left(T_{1}, T_{2}\right.$, $\left.T_{3}, \ldots, T_{m+n}\right)$ can be determined by the sources of fractures in population $Z$.

(3) The number of runs $(U)$ is a parameter that reflects the sequence of $T_{k}\left(T_{1}, T_{2}, T_{3}, \ldots, T_{m+n}\right)$, where a run is a sequence of one or more $1 \mathrm{~s}$ or $0 \mathrm{~s}$. For example, for the sequence $(1,0,0,0)$, the sequence (1) is a run with a length of 1 ; the sequence $(0,0,0)$ is another run, and its length is 3 . The $U$ in the sequence $(1,0,0,0)$ is 2 . If the null hypothesis is true, the fractures should be well mixed between $X$ and $Y$, and $U$ should be a large number. If the fractures are not well mixed between $X$ and $Y$, the length of a run is too long. Thus, $U$ should be a small number, which would indicate that the distributions of $X$ and $Y$ differ.

(4) Calculate the $p$ value (the level of significance, $p$ ). The $p$ value serves as a measure of the strength of the evidence against $H_{0}$. Usually, a fixed level of significance $\alpha=0.05$ (or 0.1 ) is used to compare with the $p$ value. A small $p$ value $(p<\alpha)$ means that $H_{0}$ is strongly rejected. For a small sample size $(m+n \leq$ 20 ), the $p$ value can be determined by $m, n$, and $U$ based on a Wald-Wolfowitz runs test table [23]. For a large sample size $(m+n>20$ or $m>12, n>12)$, an asymptotic test for the $p$ value is also available; it is based on the normal distribution of $U$, and the mean and variance of $U$ are as follows:

$$
\begin{aligned}
E(U) & =1+\frac{2 m n}{m+n} \\
\operatorname{Var}(U) & =\frac{2 m n(2 m n-m-n)}{(m+n)^{2}(m+n-1)} .
\end{aligned}
$$

Therefore, using the usual numerator continuity correction, the cutoff point (critical value) $C$ can be calculated as follows:

$$
\begin{aligned}
& C_{\mathrm{L}}=\frac{U+0.5-E(U)}{\sqrt{\operatorname{Var}(U)},} \\
& C_{\mathrm{R}}=\frac{U-0.5-E(U)}{\sqrt{\operatorname{Var}(U)}}, \\
& C= \begin{cases}-C_{\mathrm{L}}, & (U<E(U)), \\
C_{\mathrm{R}}, & (U>E(U)) .\end{cases}
\end{aligned}
$$

The one-tail $p$ value can be determined by $m, n$, and $C$ based on a Wald-Wolfowitz runs test table [24]. In practice, a two-tail test is most commonly used as a significant result that implies nonrandomness [22]. The two-tail $p$ value is calculated as follows:

$$
p= \begin{cases}2 \min \left[p\left(-C_{\mathrm{L}}\right), p\left(C_{\mathrm{R}}\right)\right], & \text { for a small sample size, } \\ 2 p\left(C_{\mathrm{R}}\right), & \text { for a large sample size. }\end{cases}
$$

To reduce the subjectivity of the patch orientations, each pair of 3D Schmidt nets is analyzed 18 times as the patch network is rotated from $0^{\circ}$ to $180^{\circ}$ in $10^{\circ}$ increments [5] along the circumference, as shown in Figure 3. In this study, the average $p$ value of the 18-patch orientations is used to determine whether the statistically homogeneous regions being compared are similar. The entire procedure of 3PSAM is performed using the program "DOMAINS," which was written by the authors, and the detailed procedures are presented as a flowchart in Figure 4.

\section{Application to Artificial Data}

3.1. Data Generation. In this study, seven simulated populations are used to verify the rationality and validity of the 3PSAM. To examine the influence of specific combination sequences of the fracture parameters on the homogeneity, four populations (data 1, 2, 2-R4, and 2-R5) are assigned to "group one." To examine the influence of different distributions of the fracture parameters on the homogeneity, five populations (data 1,2, 3, 4, and 5) are assigned to "group two." Each population is a $200 \times 4$ matrix with 200 fractures (row vectors) and 4 variables (column vectors, i.e., dip direction, dip angle, trace length, and aperture). A bivariate normal distribution (BVND), normal distribution (NORMD), and lognormal distribution (LOGD) are used to simulate the fracture orientations, trace lengths, and apertures, respectively [25-27]. It should be noted that these ideal distributions are chosen to demonstrate how the 3PSAM performs. Realistic distributions (e.g., Fisher, bivariate Fisher, or Bingham distributions for orientation; lognormal, exponential, or gamma distributions for trace length [28]) can also be used in the method. Table 3 shows the parameters of the distribution functions used to generate each population. The fractures in each population are plotted on the corresponding Schmidt plot, as shown in Figure 5.

As shown in Table 3, the main purpose of group one (data 1,2,2-R4, and 2-R5) is to examine if a specific 
TABLE 2: Example showing how two populations are ranked.

\begin{tabular}{|c|c|c|c|c|c|c|}
\hline $\begin{array}{l}\text { Patch } \\
\text { number }\end{array}$ & Population $X$ & Population $Y$ & Population $Z$ & $\begin{array}{l}\text { Ranking row vectors (fractures) in } \\
\text { ascending order of trace length }\end{array}$ & Tracking sources & $\begin{array}{l}\text { Number } \\
\text { of runs }\end{array}$ \\
\hline 1 & $m_{1}$ & $n_{1}$ & $m_{1}+n_{1}$ & $z_{1}, z_{2}, \ldots, z_{(m 1+n 1)}$ & & \\
\hline 2 & $m_{2}$ & $n_{2}$ & $m_{2}+n_{2}$ & $z_{(m 1+n 1+1),}, z_{(m 1+n 1+2), \ldots,} z_{(m 1+n 1+m 2+n 2)}$ & & \\
\hline 3 & $m_{3}$ & $n_{3}$ & $m_{3}+n_{3}$ & 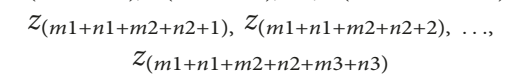 & $T_{1}, T_{2}, \ldots, T_{(m+n)}$ & $U$ \\
\hline$\vdots$ & $\vdots$ & $\vdots$ & $\vdots$ & $\vdots$ & & \\
\hline 102 & $M_{102}$ & $n_{102}$ & $m_{102}+n_{102}$ & $\begin{array}{c}z_{(m 1+n 1+m 2+n 2+\ldots+m 101+n 101+1)} \\
z_{(m 1+n 1+m 2+n 2+\ldots+m 101+n 101+2), \ldots,} z_{(m+n)}\end{array}$ & & \\
\hline
\end{tabular}

$m_{s}, n_{s}, m_{s}+n_{s},(1 \leq s \leq 102)$ are the number of fractures in the $s_{\text {th }}$ patch of populations $X, Y$, and $Z . z_{k}(1 \leq k \leq m+n)$ is a fracture (row vector) in patches of sample Z. $T_{k}(1 \leq k \leq m+n)$ is used to track the source of $z_{k}$, if $z_{k}$ is from $X, T_{k}=1$; if $z_{k}$ is from $Y, T_{k}=0$.

$\mathrm{N}$

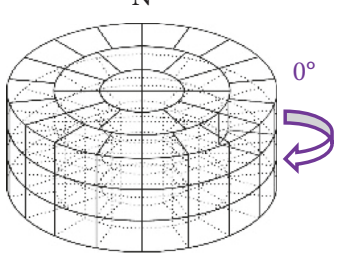

$\mathrm{N}$

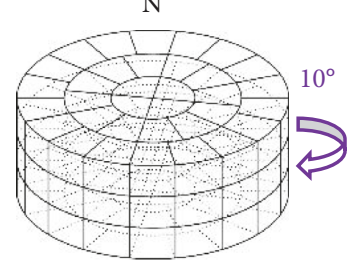

$\mathrm{N}$

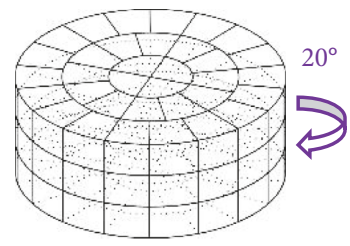

$\mathrm{N}$

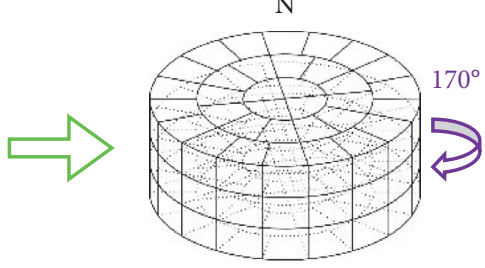

Figure 3: Rotation diagram for the 3D Schmidt net.

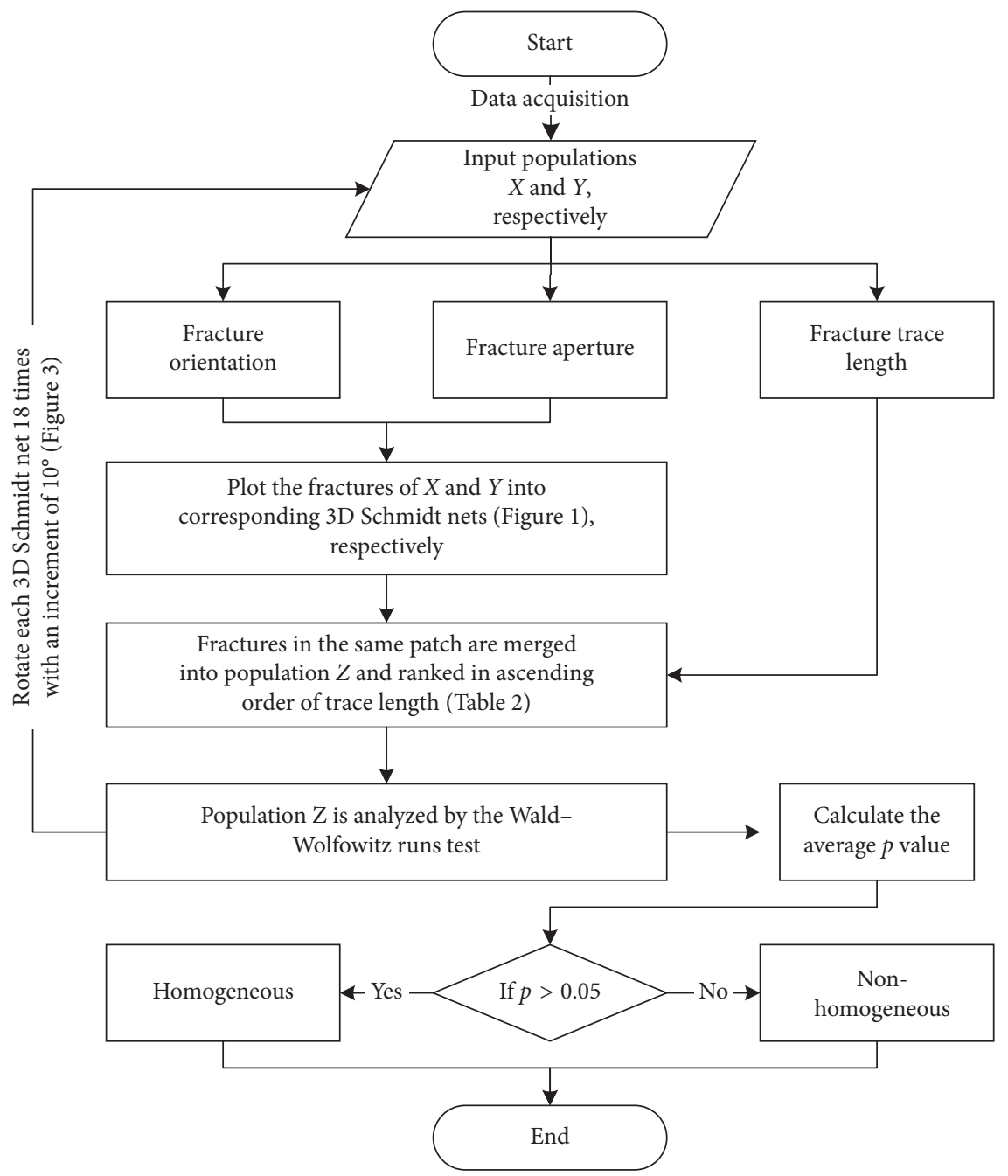

FIGURE 4: Flowchart of the procedures for the program "DOMAINS". 
TABLe 3: Parameters of the distribution functions used for the simulated fracture populations.

\begin{tabular}{|c|c|c|c|c|c|c|c|}
\hline \multirow{2}{*}{ Population } & \multicolumn{2}{|c|}{ BVND (orientation) } & \multicolumn{2}{|c|}{ NORMD (trace length) } & \multicolumn{2}{|c|}{ LOGD (aperture) } & \multirow{2}{*}{ Number of fractures } \\
\hline & Mean $\left({ }^{\circ}\right)$ & Variance (dip dir., dip) & Mean $(\mathrm{m})$ & Variance & Mean $(\mathrm{mm})$ & Variance & \\
\hline Data 1 & $180 \angle 55^{1}$ & 4000,350 & $3.5^{1}$ & 1.5 & $3^{1}$ & 400 & 200 \\
\hline Data 2 & $180 \angle 55^{2}$ & 4000,350 & $3.5^{2}$ & 1.5 & $3^{2}$ & 400 & 200 \\
\hline Data $2-\mathrm{R} 4$ & $180 \angle 55^{2}$ & 4000,350 & $3.5^{2-R 4}$ & 1.5 & $3^{2}$ & 400 & 200 \\
\hline Data 2-R5 & $180 \angle 55^{2}$ & 4000,350 & $3.5^{2}$ & 1.5 & $3^{2-\mathrm{R} 5}$ & 400 & 200 \\
\hline Data 3 & $240 \angle 45^{1}$ & 4000,350 & $3.5^{2}$ & 1.5 & $3^{2}$ & 400 & 200 \\
\hline Data 4 & $180 \angle 55^{2}$ & 4000,350 & $2.0^{1}$ & 1.5 & $3^{2}$ & 400 & 200 \\
\hline Data 5 & $180 \angle 55^{2}$ & 4000,350 & $3.5^{2}$ & 1.5 & $10^{1}$ & 400 & 200 \\
\hline
\end{tabular}

$180 \angle 55^{1 \text { (or2) }}$ : the mean orientation of a population generated by BVND in the first (or second) time. The column vectors of a fracture parameter in two populations will be same if they are generated through the same mean in the same time (e.g., the orientation column vector of data 2 equals to the orientation column vector of data 4$) \cdot 3 \cdot 5^{2-\mathrm{R} 4}$ : the trace length column vector of data $2-\mathrm{R} 4$ is rearranged from the trace length column vector of data $2.3^{2-\mathrm{R} 5}$ : the aperture column vector of data $2-\mathrm{R} 5$ is rearranged from the aperture column vector of data 2.

sequence of a column vector (fracture parameter) will affect the identification of structural domains. First, two homogeneous populations (data 1 and 2) should be predetermined by the 3PSAM. The fractures in data 1 and 2 are generated using the same distribution parameters twice. Second, the trace length column vector and the aperture column vector of data 2 are rearranged. Because only the sequences of the column vectors are changed, the rearranged column vectors will have the same distributions as the originals. For example, the fracture trace lengths of data $2-\mathrm{R} 4$ are rearranged from those of data 2 based on the pole contour plot (Figure 5(b)). To increase the differences of the corresponding trace length sequences between the two populations, the longer traces are initially assigned to those poles located in the higher density areas. Similarly, the fracture apertures of data $2-\mathrm{R} 5$ are rearranged from those of data 2 based on the pole contour plot (Figure 5(b)). The wider apertures are initially assigned to the poles located in the higher density areas. Figures 6 and 7 show the differences between data 2-R4, data 2-R5, and data 2 for the fracture trace lengths and apertures, respectively. In Figure 6, the trace length in data 2-R4 decreases with the increasing sequence number; the trace length in data 2 has no clear regularity with the increasing sequence number. In Figure 7, the aperture in data 2-R5 decreases with the increasing sequence number; the aperture in data 2 has no clear regularity with the increasing sequence number.

The main purpose of group two (data 1, 2, 3, 4, and 5) is to examine if the distribution of a column vector (fracture parameter) will affect the identification of structural domains. In group two, the frequency histograms (distributions) of data 3,4 , and 5 are different from those of data 2 in fracture orientation, trace length, and aperture, respectively. The frequency histograms of the trace lengths and apertures of the seven populations are shown in Figures 8 and 9, respectively. In Figure 8, the trace length frequency histogram of data 4 is clearly different from other data populations. In Figure 9, the aperture frequency histogram of data 5 is clearly different from other data populations.

3.2. Homogeneity Evaluation of Artificial Populations. In this study, Miller's method [5], and Song's method [15] are used to compare with the 3PSAM (Section 2) for the similarity tests between the seven populations. Table 4 shows the results of these methods. As shown in Table 4, based on the level of significance, $\alpha=0.05$; in group one, data 1,2,2-R4, and 2-R5 are statistically homogeneous regions according to Miller's method, and data 1,2, and 2R5 are statistically homogeneous regions according to Song's method. Data 1 and 2 are statistically homogeneous regions according to the 3PSAM. Both Song's method and the 3PSAM identify data 1 and 2-R4 as not being similar because the sequence of trace lengths was changed. The obvious reduction of the $p$ values of the two methods indicates that the rearranged trace length column vector of data 2 has a significant influence on the evaluation of homogeneity, and both Song's method and the 3PSAM have the ability to distinguish the changing sequence of trace lengths. Only the 3PSAM identifies data 1 and 2-R5 as not being similar because the aperture column vector sequences of data 1 and data 2-R5 are different, and the other two methods cannot consider the aperture. The obvious reduction of the $p$ value in the 3PSAM indicates that the rearranged aperture column vector of data 2 has a significant influence on the evaluation of homogeneity, and the 3PSAM can distinguish the changing sequence of apertures.

In group two, data 1 and 3 are not similar according to the three methods because the distributions of the fracture orientations in data 1 and 2 are different. This change implies that the three methods are capable of distinguishing the change of the orientation distribution. Data 1 and 4 are not similar according to Song's method and the 3PSAM because the distributions of fracture trace lengths are different in data 1 and 2. This change implies that Song's method and the 3PSAM are capable of distinguishing the change in the trace length distribution. Data 1 and 5 are not similar according to the 3PSAM because the distributions of the fracture trace apertures are different in data 1 and 2. This change implies that the 3PSAM is capable of distinguishing the change in the aperture distribution.

Therefore, three conclusions are obtained from the comparison of the results shown in Table 4. First, the sequences of the fracture parameters have an effect on the test results, as illustrated in group one. Second, the distributions 


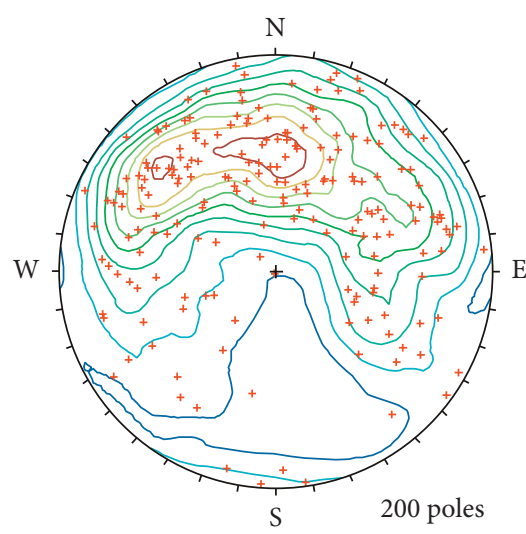

(a)

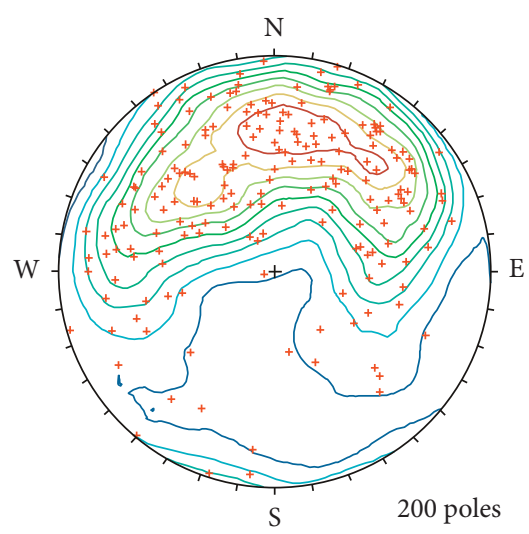

(b)

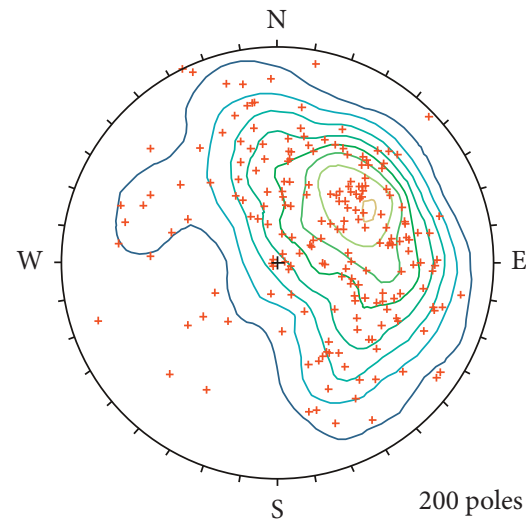

(c)

Figure 5: Schmidt plots of the simulated data: (a) data 1; (b) data 2, 2-R4, 2-R5, 4, and 5; (c) data 3.

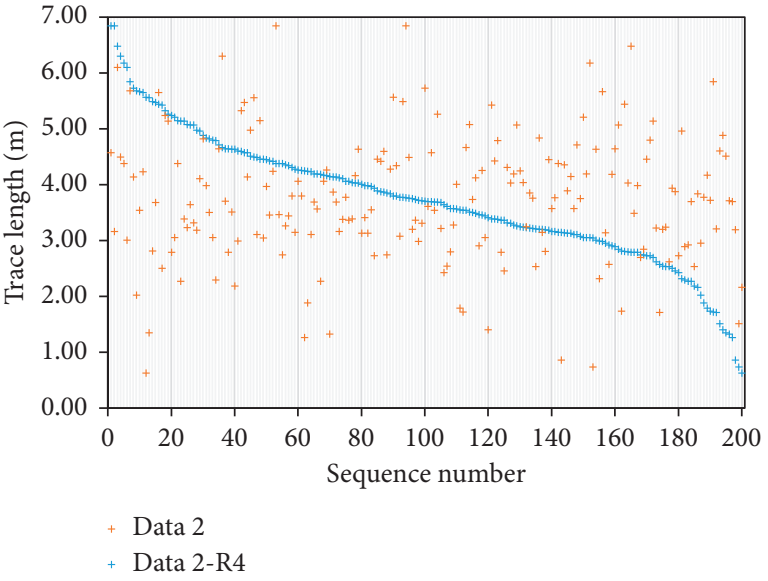

FIGURE 6: Sequences of the trace length column vector.

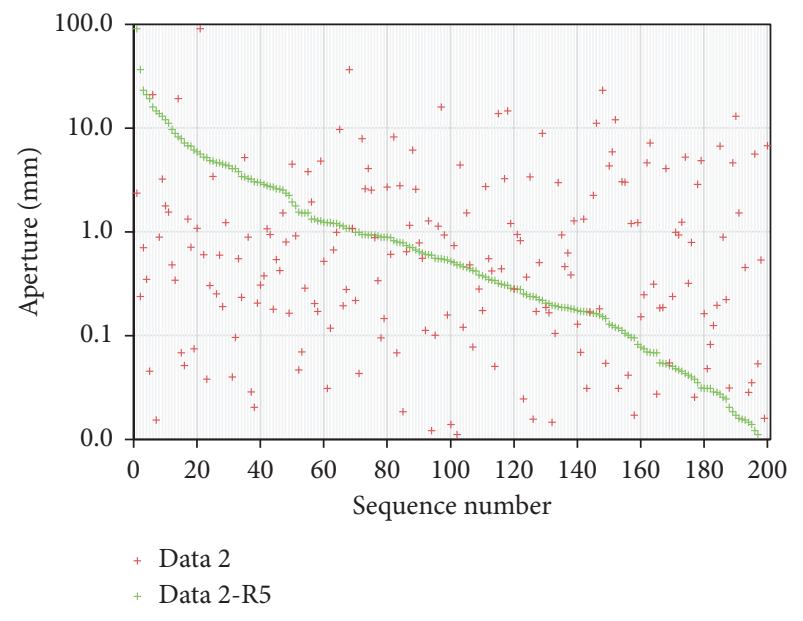

FIGURE 7: Sequences of the aperture column vector.

of the fracture parameters affect the test results, as illustrated in group two. Third, the 3PSAM is capable of distinguishing the effects caused by the sequences and distributions of the fracture parameters.

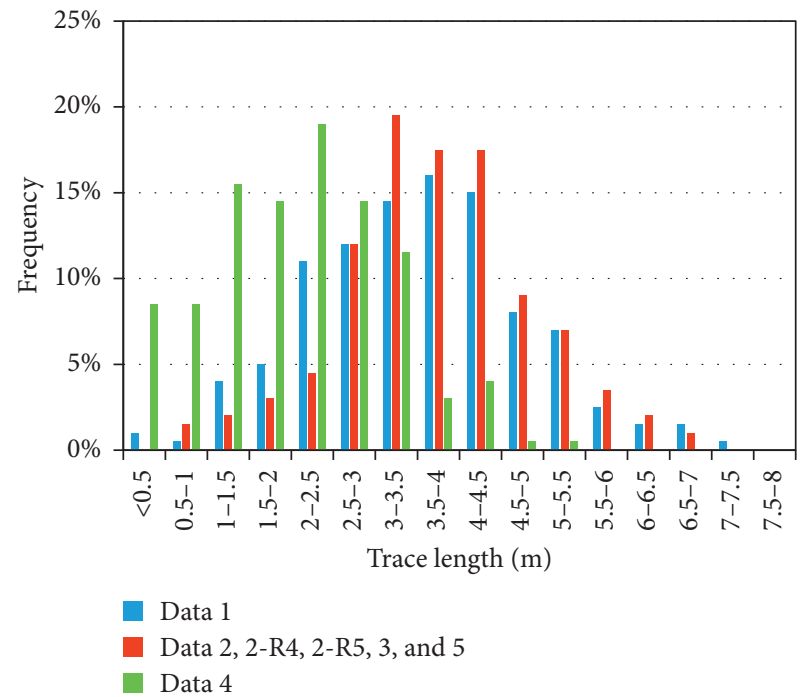

FIGURE 8: Frequency histograms of the trace lengths of the simulated populations.

\section{Application to Real Data}

4.1. Data Acquisition. The real data are collected from a planned excavation slope located in the Southeast Dalian Port, Dalian City, China (Figure 10). The main lithological unit in the study area is Epiproterozoic Sinian moderately to highly weathered slate. Fractures are very well developed in the rock mass. Five exploratory trenches and two natural outcrops are used to survey the properties of these fractures and evaluate the homogeneity of the rock mass, as shown in Figure 11. Rectangular sampling windows are used to collect data from these outcrops. The height of each rectangular window is about $2 \mathrm{~m}$, and the lengths of the windows are the lengths of the outcrops. Parameters such as the fracture orientation, trace length, aperture, infilling, roughness, and weathering were measured in each sampling window [29]. The field investigation showed that the rock strata dip steeply to the south. Small-scale joints, fissures, faults, and folds are 


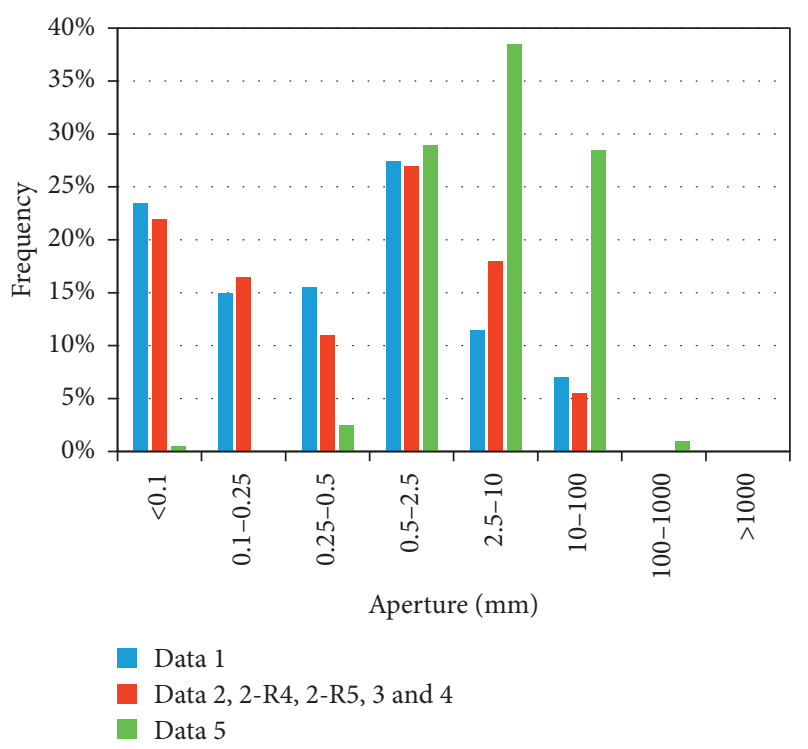

FIgURE 9: Frequency histograms of the apertures of the simulated populations.

TABLE 4: Similarity results of the simulated fracture populations.

\begin{tabular}{|c|c|c|c|c|c|c|c|c|c|c|c|c|c|}
\hline \multirow{3}{*}{ Group } & \multirow{3}{*}{$\begin{array}{l}\text { Population } \\
\text { (data) }\end{array}$} & \multicolumn{4}{|c|}{ Miller's method } & \multicolumn{4}{|c|}{ Song's method } & \multicolumn{4}{|c|}{ 3PSAM } \\
\hline & & \multicolumn{3}{|c|}{$p$ value } & \multirow{2}{*}{ Results } & \multicolumn{3}{|c|}{$p$ value } & \multirow{2}{*}{ Results } & \multicolumn{3}{|c|}{$p$ value } & \multirow{2}{*}{ Results } \\
\hline & & Max & Min & Ave & & $\operatorname{Max}$ & Min & Ave & & $\operatorname{Max}$ & Min & Ave & \\
\hline \multirow{3}{*}{ One } & 1 and 2 & 0.677 & 0.067 & 0.321 & Accepted & 1.000 & 0.176 & 0.641 & ted & 0.341 & 0.064 & 0.211 & pted \\
\hline & 1 and $2-R 4$ & 0.677 & 0.067 & 0.321 & Accepted & $\begin{array}{c}5.83 E- \\
23\end{array}$ & $\begin{array}{c}1.39 E- \\
39\end{array}$ & $\begin{array}{c}6.97 E- \\
24\end{array}$ & Rejected & $\begin{array}{c}1.06 E- \\
06\end{array}$ & $\begin{array}{c}1.65 E- \\
15\end{array}$ & $\begin{array}{c}1.38 E- \\
07\end{array}$ & Rejected \\
\hline & 1 and $2-R 5$ & 0.677 & 0.067 & 0.321 & Accepted & 1.000 & 0.176 & 0.641 & Acce & 0.051 & $\begin{array}{c}1.77 E- \\
06\end{array}$ & 0.007 & Rejected \\
\hline \multirow{3}{*}{ Two } & 1 and 3 & $\begin{array}{c}4.44 E- \\
16\end{array}$ & $\begin{array}{c}3.50 E- \\
19\end{array}$ & $\begin{array}{c}7.40 E- \\
17\end{array}$ & Rejected & 0.031 & $\begin{array}{c}5.05 E- \\
06\end{array}$ & 0.006 & Rejected & 0.024 & $\begin{array}{c}1.11 E- \\
04\end{array}$ & 0.005 & Rejected \\
\hline & 1 and 4 & 0.677 & 0.067 & 0.321 & Accepted & 0.014 & $\begin{array}{c}1.06 E- \\
06\end{array}$ & 0.002 & Rejected & 0.146 & 0.002 & 0.041 & Rejected \\
\hline & 1 and 5 & 0.677 & 0.067 & 0.321 & Accepted & 1.000 & 0.176 & 0.641 & Accepted & 0.008 & $\begin{array}{c}1.06 E- \\
06\end{array}$ & 0.002 & Rejected \\
\hline
\end{tabular}

common in the study area. Most of the fractures in the study area are dry, and the fracture surfaces are generally planar and smooth. The strata have experienced several tectonic regimes. Because of their formation, the fractures in the area always have some regularities. According to these regularities, the fractures measured in each window are considered to be a fracture population that is used in the homogeneity evaluation.

To avoid the influence of sampling bias, only the populations that were collected from windows with similar strikes are paired for the similarity test. Therefore, the test is divided into two groups according to the window orientations. Group one includes the south exploratory trench, north exploratory trench, and north outcrops 1 and 2, which strike nearly east-west. Group two includes the west exploratory trenches 1 and 2 and the east exploratory trench, which strike nearly north-south.

Because the 3PSAM considers the fracture orientation, trace length, aperture, and their combinations, other fracture parameters (e.g., infilling, roughness, weathering) are not discussed in this study. The fracture orientations in each window are plotted on Schmidt nets, as shown in Figure 12; the frequency histograms (distributions) of the trace lengths and the apertures in each window are illustrated in Figures 13 and 14, respectively.

It should be noted that aperture quantification is a very complex topic. In this study, the apertures are represented using three categories. This is because the hydrological properties of the rock masses are neglected, and only the perpendicular distance between the adjacent rock walls of an open fracture is used to represent the aperture. The aperture in Figure 14 is represented using three categories according to their general features (Table 1). The variations of these general features can affect the shear strength of rock masses [20].

4.2. Homogeneity Evaluation of Real Fracture Populations. The 3PSAM, Miller's method [5], and Song's method [15] are used to demarcate the structural domains. Table 5 shows the results of the two groups. As shown in group one, only 


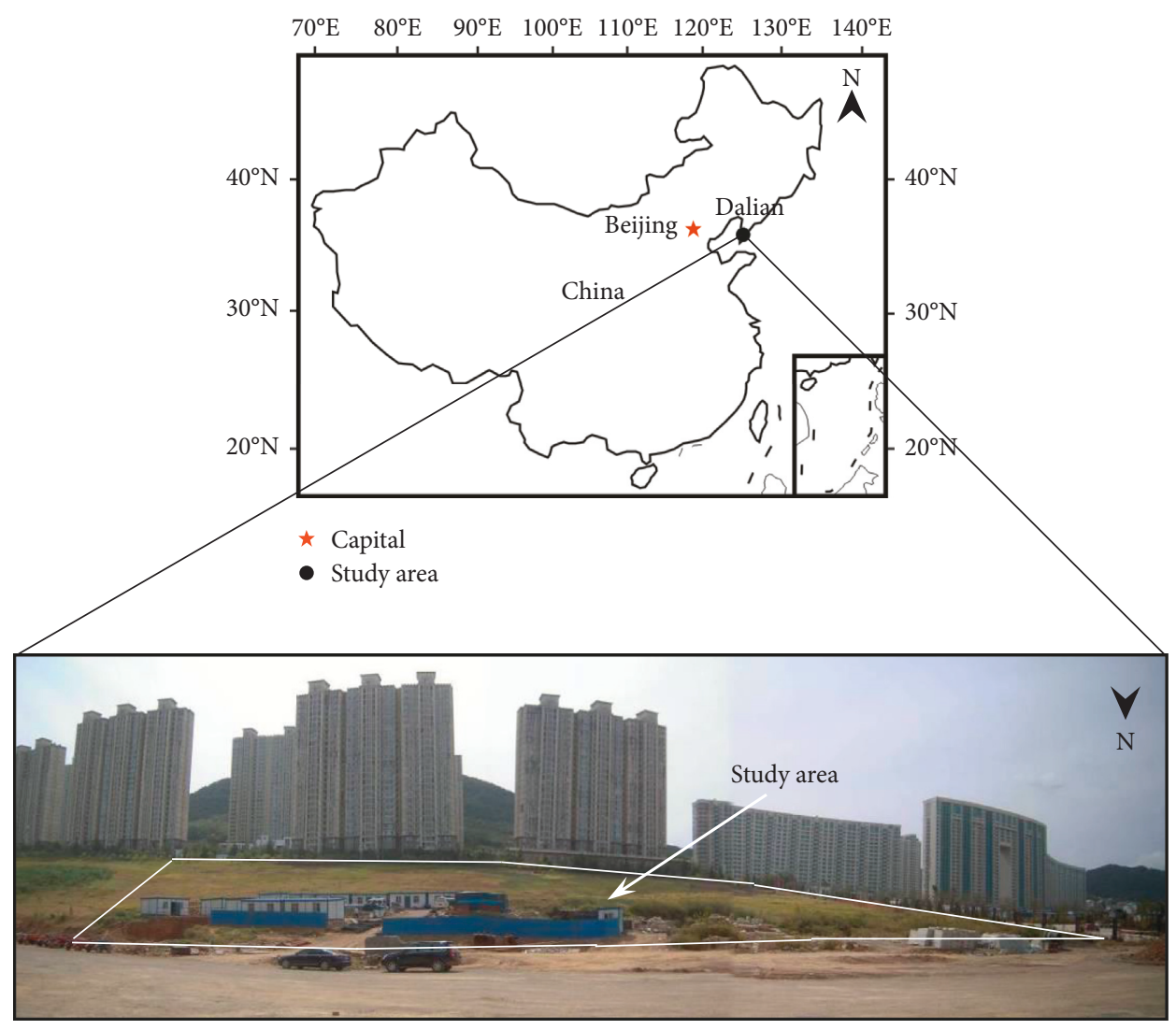

FIgURE 10: Location map of the study area.

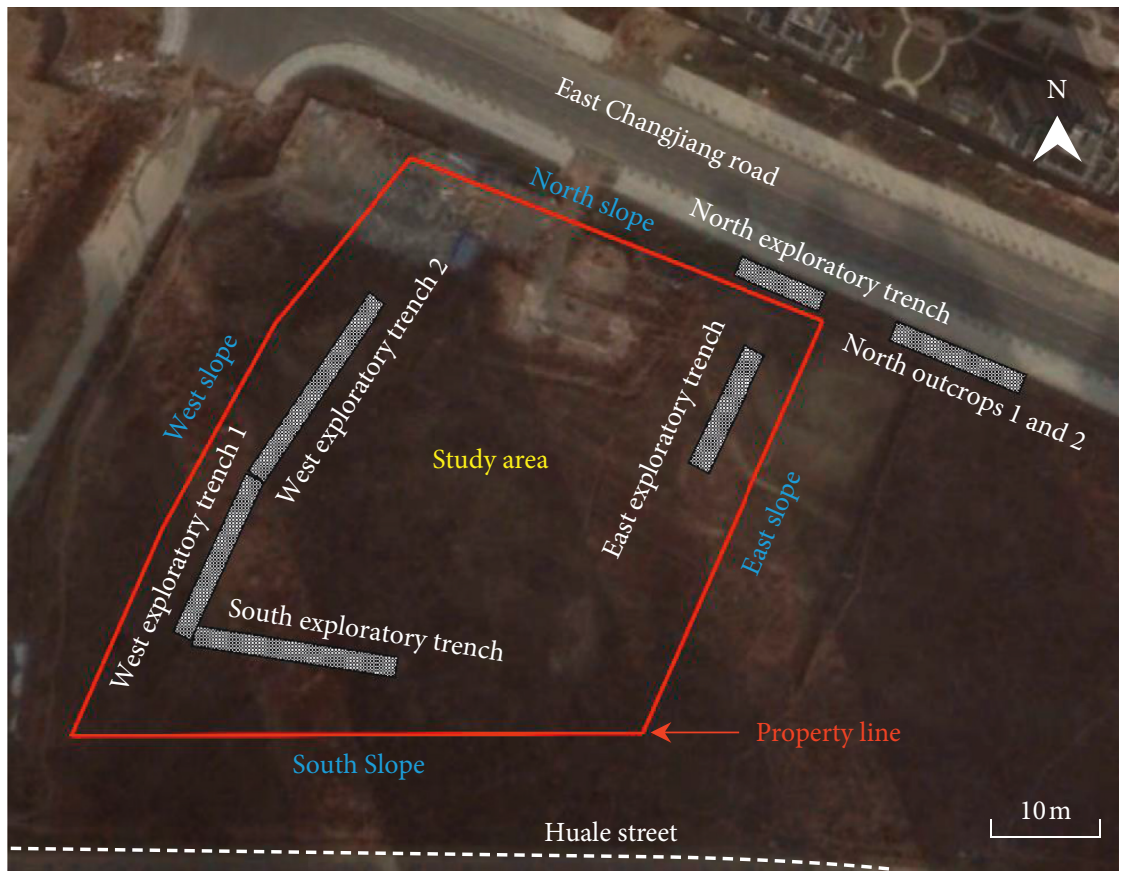

FIGURE 11: Sketch map of the outcrops.

the fracture populations from the north exploratory trench and north outcrop 2 are statistically homogeneous regions according to Miller's method. However, these two populations are not homogeneous according to Song's method and the 3PSAM. When the fracture trace length, aperture, and combinations of fracture parameters are considered in the north exploratory trench and north outcrop 2, the distributions of the fracture trace length and aperture are 


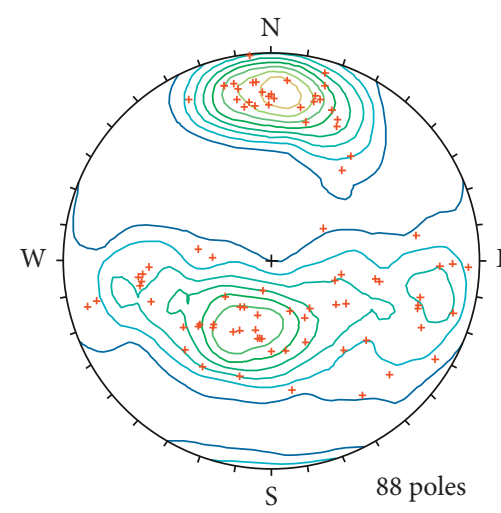

(a)

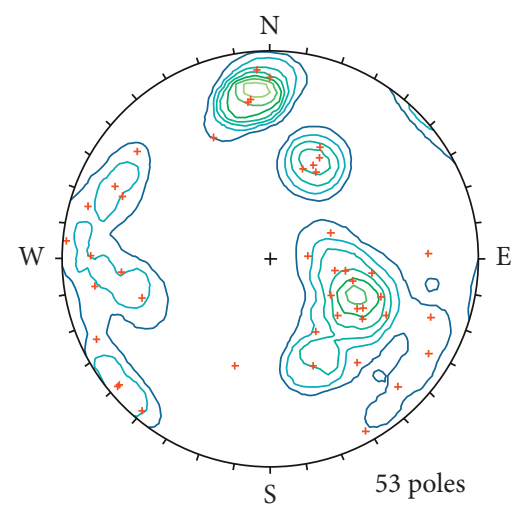

(c)

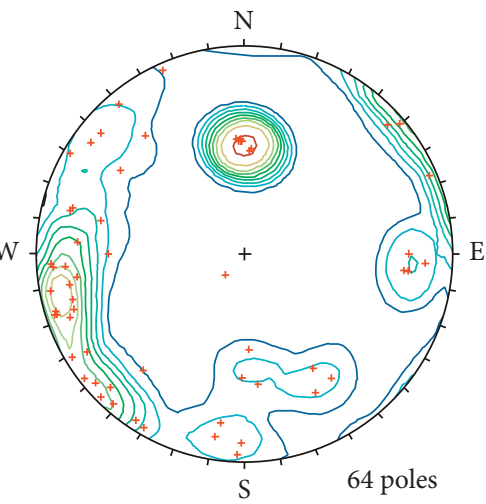

(b)

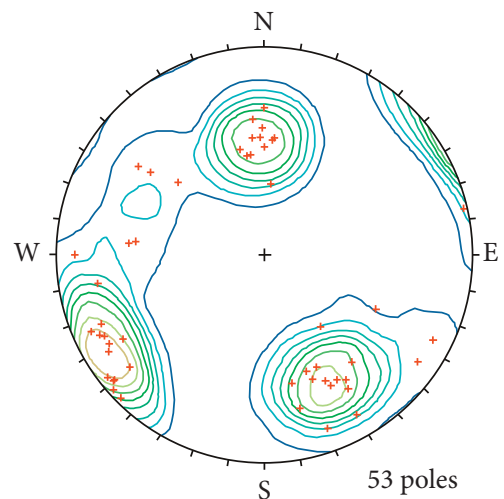

(d)

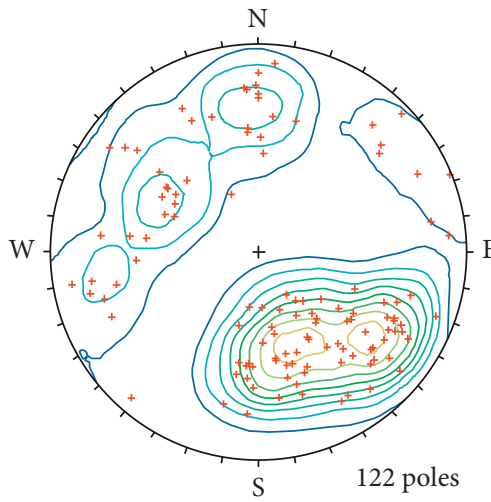

(e)

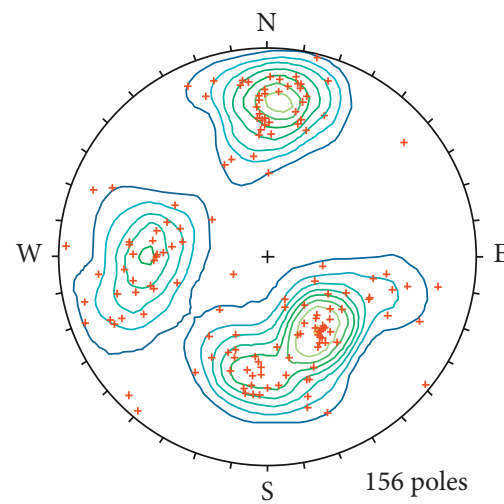

(f)

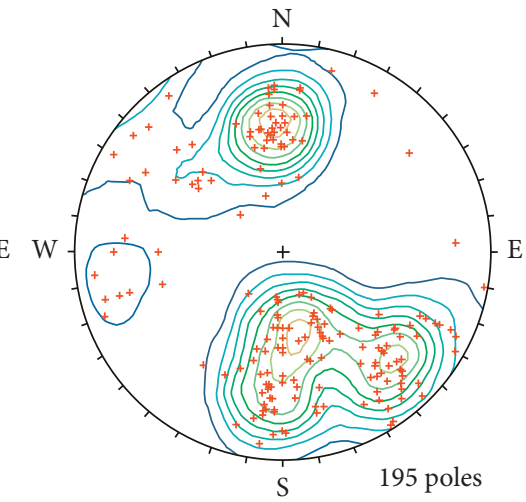

(g)

Figure 12: Schmidt plots of the fracture populations. Group one: (a) south exploratory trench; (b) north exploratory trench; (c) north outcrop 1; (d) north outcrop 2. Group two: (e) east exploratory trench; (f) west exploratory trench 1; (g) west exploratory trench 2.

apparently different (Figures 13 and 14, respectively). Therefore, the similarity between the north exploratory trench and north outcrop 2 is reduced. The fracture populations from the other outcrops in group one are not homogeneous according to the three methods. Hence, when simultaneously considering the fracture orientation, trace length, and aperture, none of the fracture populations in group one should be considered a statistically homogeneous region.

In group two, only the fracture populations from the west exploratory trench 2 and the east exploratory trench are identified as statistically homogeneous regions according to Miller's method and Song's method. This result is reasonable when only considering the orientation and trace length.
However, according to the 3PSAM, the two populations are not homogeneous because of their differences in aperture. The fracture populations from the other populations in group two are not homogeneous according to the three methods. Hence, when simultaneously considering the fracture orientation, trace length, and aperture, all of the fracture populations in group two should not be considered statistically homogeneous regions.

\section{Discussion}

The results obtained by applying the 3PSAM to seven simulated fracture populations (Table 4) show that the 


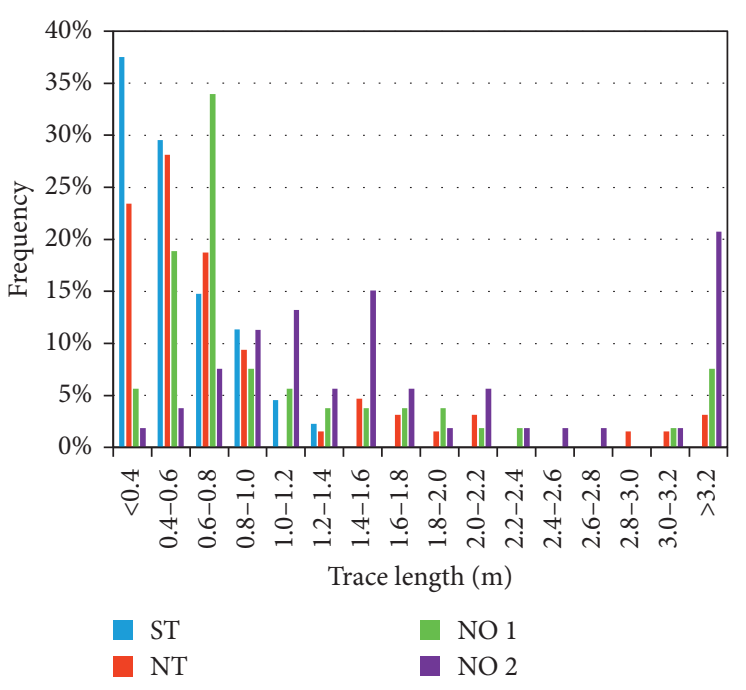

(a)

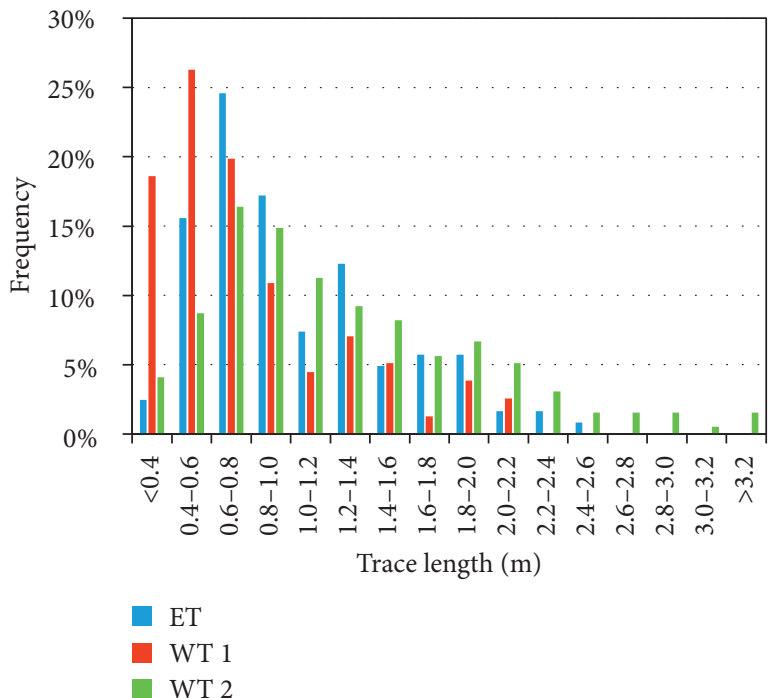

(b)

FIGURE 13: Frequency histograms of the trace lengths of the fracture populations: (a) group one: south exploratory trench (ST), north exploratory trench (NT), north outcrop (NO) 1 and 2; (b) group two: east exploratory trench (ET), west exploratory trench (WT) 1 and 2.

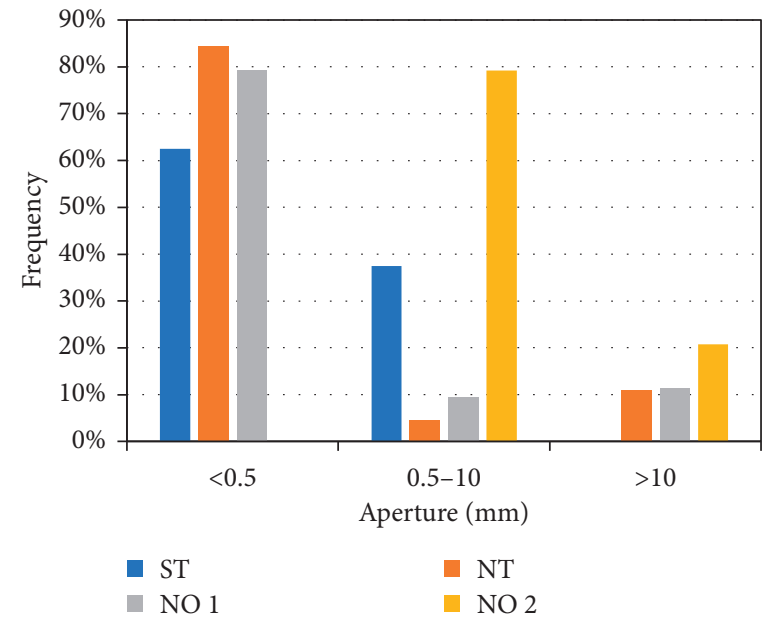

(a)

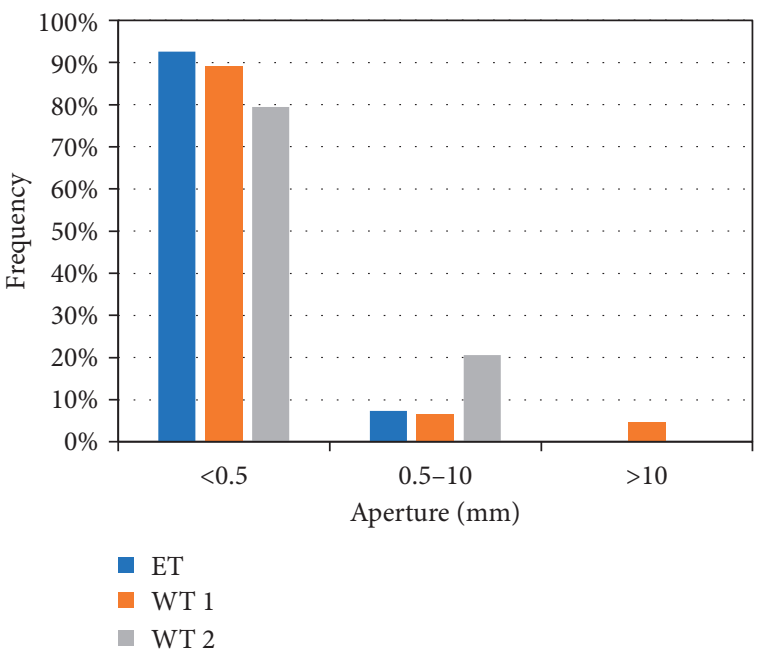

(b)

FIGURE 14: Frequency histograms of the apertures of the fracture populations: (a) group one: south exploratory trench (ST), north exploratory trench (NT), north outcrop (NO) 1 and 2; (b) group two: east exploratory trench (ET), west exploratory trench (WT) 1 and 2.

homogeneity is influenced not only by the distributions of the fracture parameters but also by the sequences of the fracture parameters. The influences of specific combinations indicate that the fracture parameters cannot be analyzed separately. In contrast to Miller's method and Song's method, the 3PSAM is capable of considering the fracture orientation, trace length, and aperture simultaneously. The merits of considering the aperture and the interactions between the fracture parameters help to demarcate structural domains in a comprehensive and reasonable way. When using the the three methods combined, the results can help us to find the factor that affects the homogeneity of two regions. For example, in data 1 and data 5, both Miller's and
Song's methods identify them as being homogeneous, but the 3PSAM identify them being nonhomogeneous. It means that they have similar properties when considering fracture orientation and trace length. But they are not homogeneous when considering fracture orientation, trace length, and aperture. Therefore, we can conclude that the homogeneity of data 1 and data 5 is affected by fracture aperture. This result can be proved by Figure 9 through a visual comparison. The distribution of fracture aperture of data 5 is different from that of data 1.

The results obtained by applying the 3PSAM to seven real fracture populations (Table 5) collected from the planned excavation slope at the Southeast Dalian Port show 
TABLE 5: Similarity results of the real fracture populations.

\begin{tabular}{|c|c|c|c|c|c|c|c|c|c|c|c|c|c|}
\hline \multirow{3}{*}{ Group } & \multirow{3}{*}{ Regions } & \multicolumn{4}{|c|}{ Miller's method } & \multicolumn{4}{|c|}{ Song's method } & \multicolumn{4}{|c|}{ 3PSAM } \\
\hline & & \multicolumn{3}{|c|}{$p$ value } & \multirow{2}{*}{ Results } & \multicolumn{3}{|c|}{$p$ value } & \multirow{2}{*}{ Results } & \multicolumn{3}{|c|}{$p$ value } & \multirow{2}{*}{ Results } \\
\hline & & Max & Min & Ave & & Max & Min & Ave & & Max & Min & Ave & \\
\hline \multirow{6}{*}{ One } & $\begin{array}{c}\text { ST and } \\
\text { NT }\end{array}$ & $\begin{array}{c}6.68 E- \\
10\end{array}$ & $\begin{array}{c}8.20 E- \\
12\end{array}$ & $\begin{array}{c}2.19 E- \\
10\end{array}$ & Rejected & $\begin{array}{c}4.29 E- \\
12\end{array}$ & $\begin{array}{c}4.38 E- \\
15\end{array}$ & $\begin{array}{c}6.11 E- \\
13\end{array}$ & Rejected & $\begin{array}{c}1.89 E- \\
14\end{array}$ & $\begin{array}{c}1.50 E- \\
18\end{array}$ & $\begin{array}{c}2.64 E- \\
15\end{array}$ & Rejected \\
\hline & $\begin{array}{l}\text { ST and } \\
\text { NO } 1\end{array}$ & 0.002 & $\begin{array}{c}7.15 E- \\
05\end{array}$ & $\begin{array}{c}7.89 E- \\
04\end{array}$ & Rejected & 0.0015 & $\begin{array}{c}8.73 E- \\
06\end{array}$ & $\begin{array}{c}4.00 E- \\
04\end{array}$ & Rejected & 0.002 & $\begin{array}{c}2.18 E- \\
07\end{array}$ & $\begin{array}{c}1.69 E- \\
04\end{array}$ & Rejected \\
\hline & $\begin{array}{l}\text { ST and } \\
\text { NO } 2\end{array}$ & $\begin{array}{c}9.03 E- \\
09\end{array}$ & $\begin{array}{c}1.38 E- \\
10\end{array}$ & $\begin{array}{c}2.80 E- \\
09\end{array}$ & Rejected & $\begin{array}{c}8.10 E- \\
11\end{array}$ & $\begin{array}{c}7.85 E- \\
14\end{array}$ & $\begin{array}{c}1.68 E- \\
11\end{array}$ & Rejected & $\begin{array}{c}5.82 E- \\
12\end{array}$ & $\begin{array}{c}3.52 E- \\
15\end{array}$ & $\begin{array}{c}1.15 E- \\
12\end{array}$ & Rejected \\
\hline & $\begin{array}{l}\text { NT and } \\
\text { NO } 1\end{array}$ & 0.002 & $\begin{array}{c}1.80 E- \\
11\end{array}$ & $\begin{array}{c}2.61 E- \\
04\end{array}$ & Rejected & 0.031 & $\begin{array}{c}3.33 E- \\
06\end{array}$ & 0.005 & Rejected & $\begin{array}{c}4.90 E- \\
04\end{array}$ & $\begin{array}{c}4.57 E- \\
07\end{array}$ & $\begin{array}{c}6.82 E- \\
05\end{array}$ & Rejected \\
\hline & $\begin{array}{l}\text { NT and } \\
\text { NO } 2\end{array}$ & 0.611 & $\begin{array}{c}1.88 E- \\
04\end{array}$ & 0.221 & Accepted & 0.002 & $\begin{array}{c}4.57 E- \\
07\end{array}$ & $\begin{array}{c}2.13 E- \\
04\end{array}$ & Rejected & $\begin{array}{c}8.39 E- \\
06\end{array}$ & $\begin{array}{c}1.05 E- \\
10\end{array}$ & $\begin{array}{c}9.10 E- \\
07\end{array}$ & Rejected \\
\hline & $\begin{array}{c}\text { NO } 1 \text { and } \\
2\end{array}$ & 0.007 & $\begin{array}{c}1.04 E- \\
04\end{array}$ & 0.002 & Rejected & 0.040 & $\begin{array}{c}8.15 E- \\
06\end{array}$ & 0.005 & Rejected & $\begin{array}{c}1.19 E- \\
04\end{array}$ & $\begin{array}{c}1.11 E- \\
08\end{array}$ & $\begin{array}{c}1.56 E- \\
05\end{array}$ & Rejected \\
\hline \multirow{3}{*}{ Two } & $\begin{array}{c}\text { ET and } \\
\text { WT } 1\end{array}$ & 0.001 & $\begin{array}{c}1.61 E- \\
12\end{array}$ & $\begin{array}{c}7.15 E- \\
05\end{array}$ & Rejected & 0.013 & $\begin{array}{c}8.21 E- \\
06\end{array}$ & 0.002 & Rejected & 0.006 & $\begin{array}{c}8.21 E- \\
06\end{array}$ & 0.001 & Rejected \\
\hline & $\begin{array}{l}\text { ET and } \\
\text { WT } 2\end{array}$ & 0.146 & 0.019 & 0.090 & Accepted & 0.203 & 0.020 & 0.085 & Accepted & 0.083 & 0.004 & 0.030 & Rejected \\
\hline & $\begin{array}{c}\text { WT } 1 \text { and } \\
2\end{array}$ & $\begin{array}{c}3.16 E- \\
07\end{array}$ & $\begin{array}{c}1.73 E- \\
11\end{array}$ & $\begin{array}{c}4.00 E- \\
08\end{array}$ & Rejected & $\begin{array}{c}5.90 E- \\
08\end{array}$ & $\begin{array}{c}1.37 E- \\
12\end{array}$ & $\begin{array}{c}6.12 E- \\
09\end{array}$ & Rejected & $\begin{array}{c}4.54 E- \\
09\end{array}$ & $\begin{array}{c}1.37 E- \\
12\end{array}$ & $\begin{array}{c}4.83 E- \\
10\end{array}$ & Rej \\
\hline
\end{tabular}

$\mathrm{ST}$ = south exploratory trench; $\mathrm{NT}=$ north exploratory trench; $\mathrm{NO}=$ north outcrop; $\mathrm{ET}=$ east exploratory trench; $\mathrm{WT}=$ west exploratory trench.

that each population should be identified as an independent structural domain. In contrast to Miller's method and Song's method, the ability of the 3PSAM to consider the differences in aperture is demonstrated by a similarity test on the two fracture populations from the west exploratory trench 2 and the east exploratory trench. Only the 3PSAM identifies the two populations as being nonhomogeneous. This result is reasonable and accurate because the differences in the apertures of the two populations are considered.

\section{Conclusion}

This study proposes a three-parameter simultaneous analysis method (3PSAM) that can simultaneously consider rock fracture orientation, trace length, and aperture to demarcate structural domains in fractured rock masses. First, a 3D Schmidt net, which represents a new comprehensive classification system, is established to characterize rock fractures based on their orientation and aperture. Two populations of rock fractures can then be projected to the corresponding patches. Second, the Wald-Wolfowitz runs test is used to perform a similarity test between two populations by ranking the row vectors (fractures) according to the trace length. Thus, the interactions between fracture parameters are taken into account. The simultaneous analysis of the three parameters is a new consideration in the 3PSAM.

The analysis showed that Miller's method considers the fracture orientation, Song's method considers the fracture orientation and trace length, and the 3PSAM simultaneously considers the fracture orientation, trace length, and aperture. Therefore, the 3PSAM can be seen as an extension of Song's method and Miller's method. All three methods exhibit reasonable and accurate performance when different fracture parameters are considered. In particular, when a combination of these methods is used, structural domains can be adequately demarcated.

For the future research of structural domain demarcation in fractured rock masses, we have three suggestions. First, the simultaneous analysis of other important fracture parameters such as spacing should be considered because fracture spacing also affects the mechanical and hydrological properties of rock masses. Second, the quantification of aperture can be more detail except considering only the mean perpendicular distance in the context (e.g., considering roughness, infilling, and water condition). This quantification is a complex topic. Third, when simultaneous analysis of multiple parameters, other similarity measures used in applied statistics (e.g., Euclidean distance, kernel method) may be introduced to demarcate structural domains.

\section{Data Availability}

Data supporting this research article are available from the corresponding author on request.

\section{Conflicts of Interest}

The authors declare that there are no conflicts of interest regarding the publication of this paper.

\section{Acknowledgments}

This work was supported by the National Natural Science Foundation of China (grant nos. U1702441, 41330636, 41402242, and 41702301), the Opening Fund of State Key Laboratory of Geohazard Prevention and Geoenvironment Protection (Chengdu University of Technology) (grant no. SKLGP2018K017), and the Graduate Innovation Fund of Jilin University. 


\section{References}

[1] ISRM, "Suggested methods for the quantitative description of discontinuities in rock masses," International Journal of Rock Mechanics and Mining Sciences and Geomechanics Abstracts, vol. 15, no. 6, pp. 319-368, 1978.

[2] G. D. Guo, A. K. Jain, W. Y. Ma, and H. J. Zhang, "Learning similarity measure for natural image retrieval with relevance feedback," IEEE Transactions on Neural Networks, vol. 13, no. 4, pp. 811-820, 2002.

[3] J. P. Vert, K. Tsuda, and B. Schölkopf, A Primer on Kernel Methods. Kernel Methods in Computational Biology, The MIT press, Cambridge, MA, USA, 2004.

[4] L. Martino, V. Elvira, and F. Louzada, "Effective sample size for importance sampling based on discrepancy measures," Signal Processing, vol. 131, pp. 386-401, 2017.

[5] S. M. Miller, "A statistical method to evaluate homogeneity of structural populations," Journal of the International Association for Mathematical Geology, vol. 15, no. 2, pp. 317-328, 1983.

[6] M. A. Mahtab and T. M. Yegulalp, "Similarity test for grouping orientation data in rock mechanics," in The 25th U.S. Symposium on Rock Mechanics (USRMS), Evanston, Illinois, 25-27 June, C. H. Dowding and M. M. Singh, Eds., pp. 495-502, American Rock Mechanics Association, New York, NY, USA, 1984.

[7] P. H. S. W. Kulatilake, D. N. Wathugala, M. Poulton, and O. Stephansson, "Analysis of structural homogeneity of rock masses," Engineering Geology, vol. 29, no. 3, pp. 195-211, 1990.

[8] P. H. S. W. Kulatilake, J. Chen, J. Teng, X. Shufang, and G. Pan, "Discontinuity geometry characterization in a tunnel close to the proposed permanent shiplock area of the Three Gorges dam site in China," International Journal of Rock Mechanics and Mining Sciences and Geomechanics Abstracts, vol. 33, no. 3, pp. 255-277, 1996.

[9] M. W. Martin and D. D. Tannant, "A technique for identifying structural domain boundaries at the EKATI diamond mine," Engineering Geology, vol. 74, no. 3-4, pp. 247-264, 2004.

[10] Y. Y. Li, Q. Wang, J. P. Chen, L. L. Han, W. Zhang, and Y. K. Ruan, "Determination of structural domain boundaries in jointed rock masses: an example from the Songta dam site, China," Journal of Structural Geology, vol. 69, pp. 179-188, 2014.

[11] Y. Y. Li, Q. Wang, J. P. Chen, L. L. Han, and S. Y. Song, "Identification of structural domain boundaries at the Songta dam site based on nonparametric tests," International Journal of Rock Mechanics and Mining Sciences, vol. 70, pp. 177-184, 2014.

[12] P. H. S. W. Kulatilake, R. Fiedler, and B. B. Panda, "Box fractal dimension as a measure of statistical homogeneity of jointed rock masses," Engineering Geology, vol. 48, pp. 217-229, 1997.

[13] W. Zhou and N. H. Maerz, "Implementation of multivariate clustering methods for characterizing discontinuities data from scanlines and oriented boreholes," Computers and Geosciences, vol. 28, pp. 827-839, 2002.

[14] P. H. Quoc, G. H. Sang, T. P. Truong, and N. Phuong, "Structural domain identification by fracture orientation and fracture density in rock mass," International Journal of Geoinformatics, vol. 8, pp. 35-40, 2012.

[15] S. Song, Q. Wang, J. Chen, Y. Li, Q. Zhang, and C. Cao, "A multivariate method for identifying structural domain boundaries in a rock mass," Bulletin of Engineering Geology and the Environment, vol. 74, no. 4, pp. 1407-1418, 2015.
[16] S. Song, Q. Wang, J. Chen, C. Cao, Y. Li, and X. Zhou, "Demarcation of homogeneous structural domains within a rock mass based on joint orientation and trace length," Journal of Structural Geology, vol. 80, pp. 16-24, 2015.

[17] Y. Li, Q. Wang, J. Chen, S. Song, Y. Ruan, and Q. Zhang, "A multivariate technique for evaluating the statistical homogeneity of jointed rock masses," Rock Mechanics and Rock Engineering, vol. 48, no. 5, pp. 1821-1831, 2015.

[18] W. Zhang, Q. Zhao, R. Huang, J. Chen, Y. Xue, and P. Xu, "Identification of structural domains considering the size effect of rock mass discontinuities: a case study of an underground excavation in Baihetan Dam, China," Tunnelling and Underground Space Technology, vol. 51, pp. 75-83, 2016.

[19] S. Song, F. Sun, W. Zhang et al., "Identification of structural domains by considering multiple discontinuity characteristics: a case study of the Songta Dam," Bulletin of Engineering Geology and the Environment, vol. 77, no. 4, pp. 1589-1598, 2017.

[20] E. Hoek and J. W. Bray, Rock Slope Engineering, Taylor and Francis: The Institution of Mining and Metallurgy, London, UK, 4th edition, 1981.

[21] A. Wald and J. Wolfowitz, "On a test whether two samples are from the same population," Annals of Mathematical Statistics, vol. 11, no. 2, pp. 147-162, 1940.

[22] R. C. Magel and S. H. Wibowo, "Comparing the powers of the Wald-Wolfowitz and Kolmogorov-Smirnov tests," Biometrical Journal, vol. 39, no. 6, pp. 665-675, 1997.

[23] P. Sprent and N. C. Smeeton, Applied Nonparametric Statistical Methods, Chapman \& Hall/ CRC, Boca Raton, FL, USA, 2007.

[24] D. H. Yi and H. Q. Dong, Non-parameter Statistics: Methods and Application, China Statistics Press, Beijing, China, 2009.

[25] S. D. Priest, Discontinuity Analysis For Rock Engineering, Chapman \& Hall, London, UK, 1993.

[26] J. P. Chen, S. F. Xiao, and Q. Wang, Three-Dimensional Network Modeling of Random Fractures, Northeast Normal University Press, Changchun, China, 1995.

[27] D. Marcotte and E. Henry, "Automatic joint set clustering using a mixture of bivariate normal distributions," International Journal of Rock Mechanics and Mining Sciences, vol. 39, no. 3, pp. 323-334, 2002.

[28] G. B. Baecher, "Statistical analysis of rock mass fracturing," Journal of the International Association for Mathematical Geology, vol. 15, no. 2, pp. 329-348, 1983.

[29] X. Zhou, J. Chen, Y. Chen, S. Song, M. Shi, and J. Zhan, "Bayesian-based probabilistic kinematic analysis of discontinuity-controlled rock slope instabilities," Bulletin of Engineering Geology and the Environment, vol. 76, no. 4, pp. 1249-1262, 2017. 


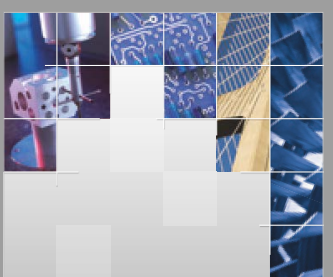

\section{Enfincering}
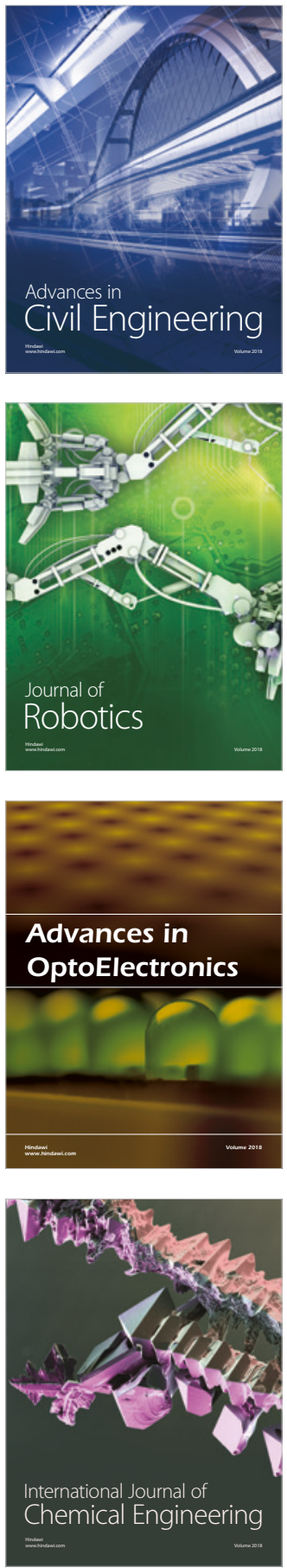

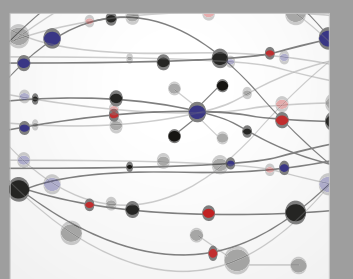

\section{Rotating \\ Machinery}

The Scientific World Journal

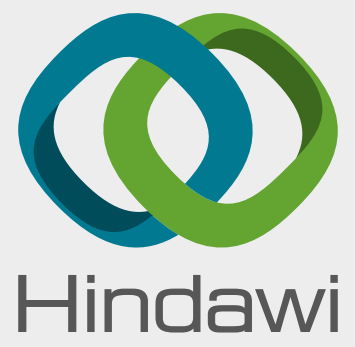

Submit your manuscripts at

www.hindawi.com
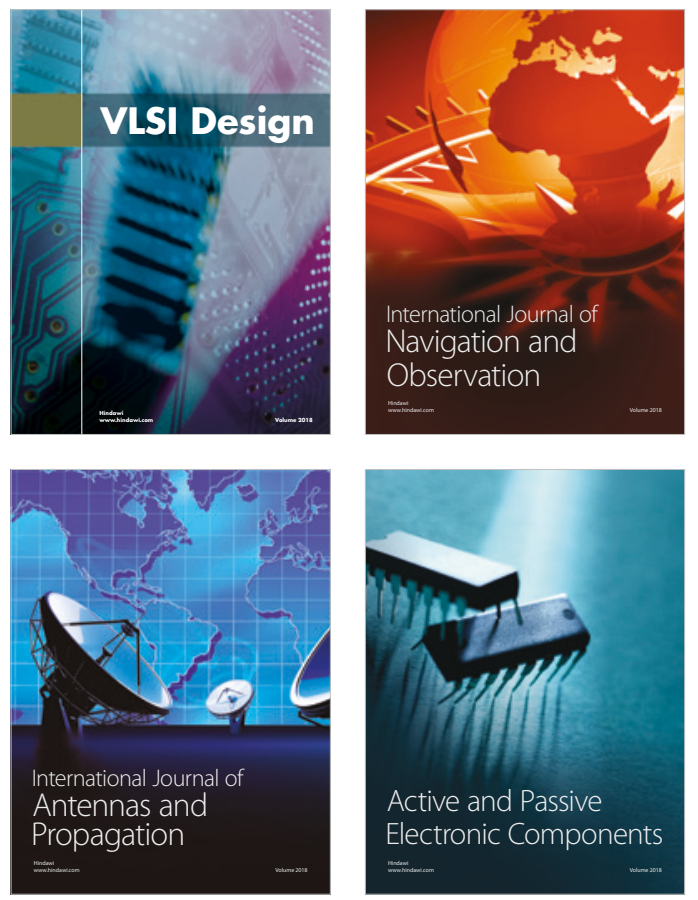
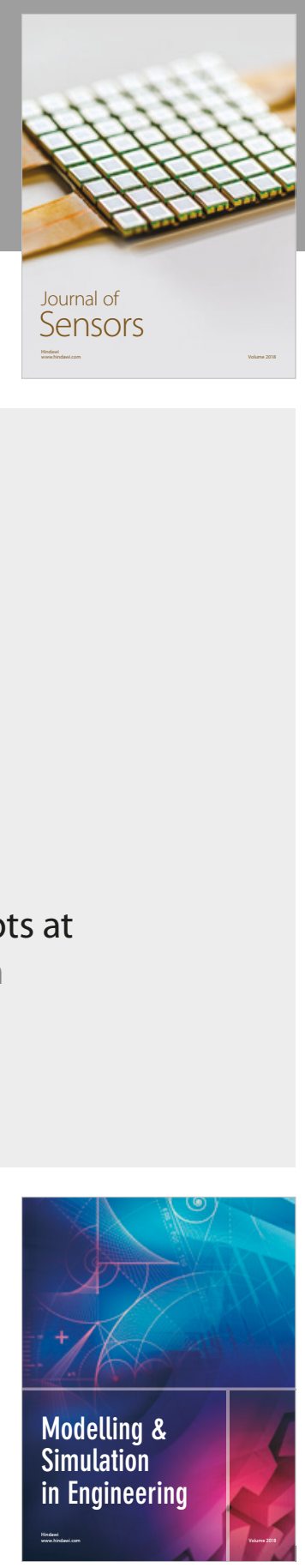

\section{Advances \\ Multimedia}
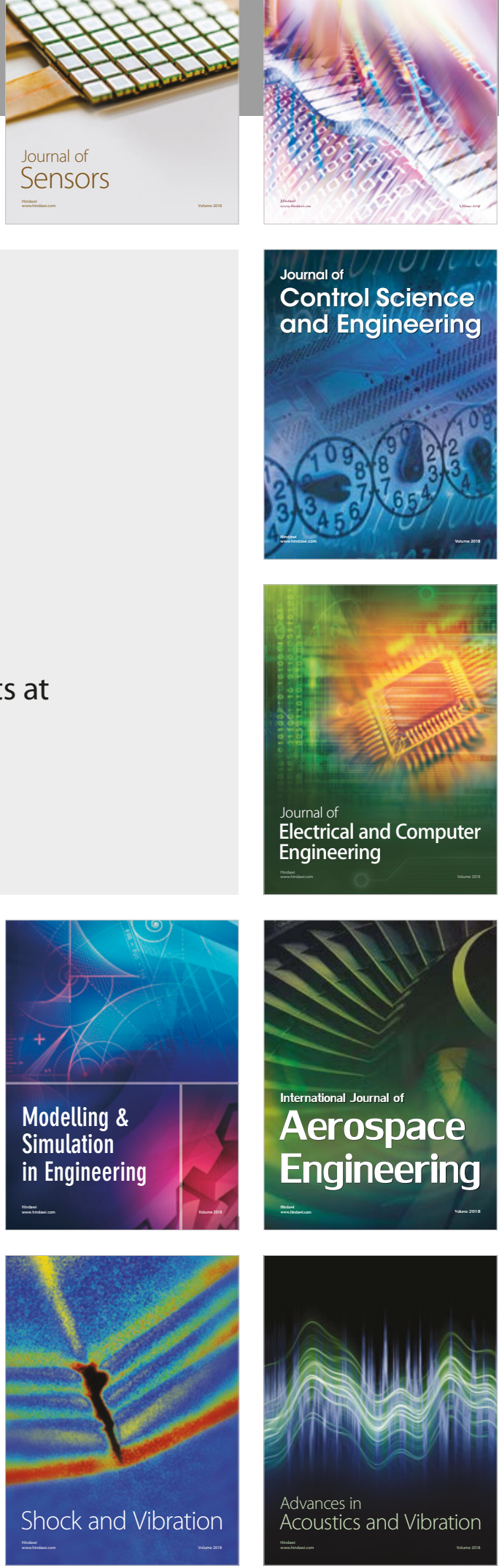